\title{
Glycyrrhizic acid restrains airway inflammation and remodeling in asthma via the TGF-ß1/Smad signaling pathway
}

\author{
ZIPING YAO and YANLING FU \\ College of Traditional Chinese Medicine, Beijing University of Chinese Medicine, Beijing 100029, P.R. China
}

Received April 14, 2020; Accepted September 3, 2020

DOI: $10.3892 /$ etm.2021.9892

\begin{abstract}
The anti-inflammatory effects of glycyrrhizic acid (GA) against asthma have previously been reported; however, the underlying molecular mechanism of GA in asthma has not yet been elucidated. Thus, the present study aimed to determine the function and potential molecular mechanism of GA for modulating the transforming growth factor- $\beta 1$ (TGF- $\beta 1) / \mathrm{Smad}$ signaling pathway in asthma-associated airway inflammation and remodeling. In order to study the mechanism of GA on airway inflammation and airway remodeling in asthmatic mice, a mouse model of chronic asthma was constructed. A total of 50 female mice were randomly assigned into five groups (10 mice/group), as follows: Blank group, asthma group, GA group, dexamethasone group and GA + TGF- $\beta 1$ group. Hematoxylin and eosin, and Masson staining were performed to assess the airway inflammation and remodeling in mice with ovalbumin (OVA)-induced asthma. The serum levels of interleukin (IL)-4, IL-5, IL-13 and IL-17 in mice were assessed via the enzyme-linked immunosorbent assay. Reverse transcription-quantitative PCR and western blot analyses were performed to detect the levels of TGF- $\beta 1$ and Smads in lung tissues of each group of mice. The results demonstrated that GA and dexamethasone treatment mitigated airway inflammation, inflammatory cell infiltration and airway remolding, with a concomitant decrease in the expression levels of IL-4, IL-5, IL-13 and IL-17, in mice with OVA-induced asthma. In addition, the levels of TGF- $\beta 1$ and Smad 2 notably decreased, while Smad7 expression increased in the GA and dexamethasone groups compared with the asthma group. Furthermore, histopathological morphometry exhibited significantly elevated inflammatory cell infiltration, airway wall and smooth muscle, collagen secretion and inflammatory cytokines in the serum of mice in the GA + TGF- $\beta 1$ group compared with the GA group. Taken together, the results of the present study suggest that
\end{abstract}

Correspondence to: Dr Yanling Fu, College of Traditional Chinese Medicine, Beijing University of Chinese Medicine, 11 North Third Ring East Road, Chaoyang, Beijing 100029, P.R. China

E-mail: yaoziping1978@163.com

Key words: glycyrrhizic acid, asthma, airway inflammation, airway remodeling, TGF- $\beta 1 /$ Smad signaling pathway
GA ameliorates airway inflammation and remodeling via the TGF- $\beta 1 /$ Smad signaling pathway in mice with asthma.

\section{Introduction}

Asthma is one of the major chronic and non-communicable syndromes in both children and adults, whereby 334 million people suffer from this disease worldwide (1). The pathophysiological process of asthma involves several types of cells and cellular components, among which airway remodeling is a well-known characteristic caused by recurrent injury and repair processes initiated by chronic inflammation (2). As a chronic inflammatory disorder of the respiratory air passages, asthma may initially be reversible but progresses into an irreversible state due to airway remodeling (3). Moreover, the prevalence of asthma has been increasing worldwide with a yearly rate of $1.8 \%$, and 300 million people affected are in mainland China, causing a substantial economic burden $(4,5)$; therefore, understanding the precise pathophysiology of asthma is paramount to achieve optimal management.

Recent research has focused on the identification of candidate pharmacologically active ingredients in natural herbs to prevent and treat asthma (6-9). Glycyrrhizic acid (GA), also known as glycyrrhizin, is one of the most important bioactive constituents isolated from the traditional Chinese herb Glycyrrhiza uralensis, which has been demonstrated to display multiple pharmacological activities, such as anticancer, antiviral and anti-inflammatory effects (10-12). In addition, the number of studies focusing on the protective effects of GA against asthma have increased; however, its underlying molecular mechanism involved in asthma remains unknown $(13,14)$.

Research has reported that targeting the transforming growth factor- $\beta 1$ (TGF- $\beta 1$ )/Smad signaling pathway may provide a novel therapeutic method for asthma airway remodeling (15). TGF-1 is considered the main regulator of airway remodeling in asthma and directly affects the deposition of collagen in the airway wall (16). The Smad protein, an important member of the TGF- $\beta$ signal transduction system, is central to the signal transduction pathway $(17,18)$. However, whether GA attenuates asthma symptoms through the TGF- $\beta 1 / \mathrm{Smad}$ signaling pathway remains unclear. Thus, the present study aimed to investigate the function of GA on the TGF-1/Smad signaling pathway in airway inflammation and remodeling in ovalbumin (OVA)-induced asthma mouse models, in order to provide a theoretical background for asthma management. 


\section{Materials and methods}

Experimental animals. A total of 50 healthy female BALB/c mice (20-22 g) aged 10-12 weeks were obtained from Hunan SJA Laboratory Animal Co., Ltd. (Changsha, China) and housed in the Laboratory Animal Center of Medical College of Hunan Normal University. All mice were fed in an animal house at a relative humidity of $40-60 \%$, temperature of $22-26^{\circ} \mathrm{C}$ and sufficient light. In addition, the mice had free access to food and water in a controlled environment (sterile food and drinking water in accordance with room pressure standard). All animal experiments were approved by the local Ethics Committee of Beijing University of Chinese Medicine and performed in accordance with the Guide for the Care and Use of Laboratory Animals (19).

Animal grouping and model establishment. A total of 50 female mice were randomly assigned into five groups (10 mice/group), as follows: Blank group, asthma group, GA group $(80 \mathrm{mg} / \mathrm{kg}$; cat.no. 1295888; Sigma-Aldrich; Merck KGaA), dexamethasone group (2 mg/kg; cat. no. D1756; Sigma-Aldrich; Merck KGaA) and the GA + TGF- $\beta 1$ group. During the course of asthma sensitization, the mice in the asthma, GA, dexamethasone and GA + TGF- $\beta 1$ groups were intraperitoneally injected with $0.2 \mathrm{ml}$ sensitizing liquid supplemented with $200 \mu \mathrm{g} / \mathrm{ml}$ OVA (Sigma-Aldrich; Merck KGaA) and $20 \mathrm{mg} / \mathrm{ml}$ aluminum hydroxide suspension (Chengdu Kelong Chemical Co., Ltd.), at days 0,7 and 14 . In addition, mice in the GA + TGF- $\beta 1$ group were intraperitoneally injected with exogenous recombinant TGF- $\beta 1$ (0.1 $\mu \mathrm{g} / \mathrm{rat} ; 100-21 \mathrm{C}$; PeproTech, Inc.). Mice in the blank group were simultaneously given intraperitoneal injections of the same amount of normal saline solution $(0.7 \%)$ as the control group. After the mice were in phase excitation from the 14th day, the OVA solution $(0.2 \mathrm{ml})$ was delivered into the noses of mice in the asthma, GA, dexamethasone and GA + TGF- $\beta 1$ groups to construct a chronic asthma model, and the blank group received a continuous nasal drip with the same amount of normal saline. The excitation period lasted for 6 days.

In the excitation phase, mice were anesthetized by intraperitoneal injection with $250 \mathrm{mg} / \mathrm{kg}$ tert butyl alcohol (cat. no. 471712; Sigma-Aldrich, Merck KGaA) and tribromethanol (cat. no. T48402; Sigma-Aldrich, Merck KGaA) mixture (diluted with PBS, $x 40$ ). The OVA solution was delivered to the nose of mice using a $50 \mu \mathrm{l}$ micropump (Shanghai Elab Scientific Instruments). At the time of excitation, mice in the GA and dexamethasone groups were intraperitoneally injected with GA and dexamethasone $30 \mathrm{~min}$ before the nasal drip according to 80 and $2 \mathrm{mg} / \mathrm{kg}$ standards (20), respectively. The general conditions of the mice in each group, including their appetites, fur, mental conditions, weight changes and airway pathological changes were observed and recorded every day.

Preparation for lung tissue slices. All mice were anesthetized by injection with $250 \mathrm{mg} / \mathrm{kg}$ tert butyl alcohol (cat. no. 471712; Sigma-Aldrich, Merck KGaA) and tribromethanol (cat. no. T48402; Sigma-Aldrich, Merck KGaA) mixture 24 h after model establishment. Subsequently, their eyeballs were fully exposed, and blood was collected via orbital blood sampling and transferred into a sodium citrate anticoagulation tube. The tube was centrifuged for $10 \mathrm{~min}$ at room temperature at $1,000 \times \mathrm{g}$ prior to collection of the supernatant and storage at $-20^{\circ} \mathrm{C}$.

The mice were sacrificed by cervical vertebrae dislocation, and the thoracic cavity was immediately opened to expose the lung tissues. Normal saline $(0.7 \%)$ was injected into the lung tissues for perfusion and rinsed using $10 \mathrm{ml}$ injection syringe until the lung tissues blanched. The right lung tissues were rapidly extracted and placed in liquid nitrogen for storage, whereas the left lung tissues were harvested and fixed in $4 \%$ paraformaldehyde for $24 \mathrm{~h}$ (room temperature) to prepare paraffin sections. The tissue sections were subsequently subjected to hematoxylin and eosin (H\&E) and Masson staining.

$H \& E$ staining. The paraffin-embedded tissue samples were cut into $5-\mu \mathrm{m}$-thick sections and deparaffinized in xylene I and xylene II for $15 \mathrm{~min}$ each (room temperature), with an ethanol wash (two times, $5 \mathrm{~min}$ each) at room temperature. The tissue sections were subsequently rehydrated in a descending ethanol series (95, 80 and 70\%; 5 min each) and washed two times with deionized water. The paraffin sections were dewaxed, stained with hematoxylin for $10 \mathrm{~min}$ (room temperature), washed in running water for 5 min followed by differentiation in $1 \%$ hydrochloric acid ethanol solution for $30 \mathrm{sec}$, and re-washed in running water. Tissue sections were subsequently stained with $1 \%$ eosin for $30 \mathrm{sec}$ at room temperature and washed in running water, prior to rehydration in an ethanol series $(95,95$, 100 and $100 \%$; 1 min each) and cleared in xylene (two times, 3 min each). Tissue sections were sealed with a neutral resin seal sheet for observation under a fluorescence microscope (DM3000 and DM3000 LED; Leica Microsystems GmbH).

Masson staining. The paraffin-embedded tissue samples were cut into $5-\mu \mathrm{m}$ thick sections and deparaffinized in xylene I and xylene II for $15 \mathrm{~min}$ each, with an ethanol wash (two times, $5 \mathrm{~min}$ each) at room temperature. The tissue sections were subsequently rehydrated in a descending an ethanol series $(95,80$ and 70\%, 5 min each), with repeated cleaning cycles. Tissue sections were subsequently stained with Masson trichrome stain (Beijing Solarbio Science \& Technology Co., Ltd.) for 5-10 $\mathrm{min}$ (room temperature) and rinsed with $2 \%$ acetic acid solution, prior to differentiation in $1 \%$ molybdophosphoric acid aqueous solution for 3-5 min. Aniline solution was subsequently added to the tissue sections for $5 \mathrm{~min}$, followed by a final rinse with $0.2 \%$ glacial acetic acid solution. Tissue sections were rehydrated in an ethanol series (95, 95, 100 and 100\%; $1 \mathrm{~min}$ each) and cleared in xylene (two times, 3 min each), prior to sealing with a neutral resin for observation using an optical microscope (20X objective). The thickness of the airway wall (Wat, $\mu \mathrm{m}^{2}$ ), smooth muscle layer (Wam, $\mu \mathrm{m}^{2}$ ), thickness of the inside airway wall (Wai, $\mu \mathrm{m}^{2}$ ), collagen deposition under the basement membrane (Wcol, $\mu \mathrm{m}^{2}$ ) and basement membrane perimeter $(\mathrm{Pbm})$ were measured using Image-Pro Plus 6.0 (IPP 6.0) software (Media Cybernetics, Inc.).

Periodic acid-Schiff (PAS) staining. Goblet cell hyperplasia was assessed via PAS staining. The paraffin-embedded lung tissues (5- $\mu$ m-thick) were deparaffinized in xylene I and II for 
$20 \mathrm{~min}$, and rehydrated in ethyl alcohol I, ethyl alcohol II and $75 \%$ alcohol for $5 \mathrm{~min}$ each, prior to rinsing with tap water for 2 min. Tissue sections were subsequently treated with periodic acid for $15 \mathrm{~min}$ and rinsed with running water for $2 \mathrm{~min}$, prior to staining with Coleman's Schiff stain at room temperature in the dark for $30 \mathrm{~min}$. Sections were counterstained with hematoxylin and differentiated in $1 \%$ hydrochloric acid ethanol (rinsed after each step). Tissue sections were rehydrated in ethyl alcohol I, ethyl alcohol II and ethyl alcohol III (5 min each), cleared in xylene I and II (5 min each) and sealed in neutral resin prior to observation under an optical microscope (20X objective). The PAS-positive area (APAS+) and basement membrane perimeter $(\mathrm{Pbm})$ was determined using IPP 6.0 software. The degree of goblet cell hyperplasia was represented as $\mathrm{APAS}^{+} / \mathrm{Pbm}\left(\mu \mathrm{m}^{2} / \mu \mathrm{m}\right)$.

Enzyme-linked immunosorbent assay (ELISA). ELISA was used to detect inflammatory factors in serum of rats. The levels of inflammatory cytokines interleukin (IL)-4, IL-5, IL-13 and IL-17 in mouse serum in each group were determined using the following Mouse ELISA kits: IL-4 (cat. no. BMS613), IL-5 (cat. no. EMIL5ALPHA), IL-13 (cat. no. BMS6015) and IL-17 (cat. no. BMS6001; all purchased from Invitrogen; Thermo Fisher Scientific, Inc.), according to the manufacturer's protocols. The absorbance value (OD value) of each well was measured at a wavelength of $450 \mathrm{~nm}$, using a multimode microplate (Synergy 2; BioTek Instruments, Inc.).

Reverse transcription-quantitative PCR (RT-qPCR). Total RNA was extracted from lung tissues using TRIzol ${ }^{\circledR}$ reagent (Thermo Fisher Scientific, Inc.), and the purity and concentration of RNA were detected using a multimode microplate (BioTek Instruments, Inc.). Following quantification, total RNA was reverse transcribed into cDNA using a Path-ID ${ }^{\mathrm{TM}}$ Multiplex One-Step RT-PCR kit (cat. no. 4442136; Applied Biosystems; Thermo Fisher Scientific, Inc.). qPCR with SYBR-Green detection was subsequently performed using a CFX Connect fluorescence quantitative PCR detection system (Bio-Rad Laboratories, Inc.). The primer sequences are presented in Table I. The following thermocycling conditions were used for qPCR: Initial denaturation at $95^{\circ} \mathrm{C}$ for $10 \mathrm{~min}$, denaturation at $95^{\circ} \mathrm{C}$ for $10 \mathrm{sec}$, annealing at $60^{\circ} \mathrm{C}$ for $20 \mathrm{sec}$ and a final extension at $72^{\circ} \mathrm{C}$ for $34 \mathrm{sec}$ for 40 total cycles. Relative mRNA levels were quantified using the $2-^{\Delta \Delta C q}$ method (21) and normalized to the internal reference gene GAPDH.

Western blotting. The right lung tissue of mice was ground into a powder under liquid nitrogen and subsequently lysed using lysis buffer for $30 \mathrm{~min}$ on ice. Cells were centrifuged at $7,500 \mathrm{x} \mathrm{g}$ for $10 \mathrm{~min}$ at $4^{\circ} \mathrm{C}$. The supernatant was collected, and total protein was quantified using a bicinchoninic acid assay (Vazyme Biotech Co., Ltd.) and $30 \mu \mathrm{g}$ protein/lane was separated via SDS-PAGE on a $10 \%$ gel. The separated proteins were subsequently electroblotted onto polyvinylidene difluoride membranes (EMD Millipore) and blocked with 5\% nonfat milk at room temperature for $1 \mathrm{~h}$. The membranes were incubated with primary antibodies against: Rabbit anti-mouse TGF- $\beta 1$ (cat. no. 3711S; 1:1,000; Cell Signaling Technology, Inc.), Smad2 (cat. no. 5339S; 1:1,000; Cell Signaling Technology, Inc.) and Smad7 (cat. no. ab216428; 1:1,000;
Table I. Primer sequences used for quantitative PCR.

\begin{tabular}{ll}
\hline Primer & \multicolumn{1}{c}{ Sequence $\left(5^{\prime}-3^{\prime}\right)$} \\
\hline TGF- $\beta 1$ & F: GTGTGGAGCAACATGTGGAACTCTA \\
& R: TTGGTTCAGCCACTGCCGTA \\
SMAD2 & F: CCACTACCAGAGGGTGGAGA \\
& R: TAACTGGCTGCAATCCAAG \\
SMAD7 & F: AGGCATTCCTCGGAAGTCAA \\
& R: TGGACAGTCTGCAGTTGGTTTG \\
GAPDH & F: GTCGATGGCTAGTCGTAGCATCGAT \\
& R: TGCTAGCTGGCATGCCCGATCGATC
\end{tabular}

TGF- $\beta 1$, transforming growth factor- $\beta 1$; F, forward; R, reverse.

Abcam) overnight at $4^{\circ} \mathrm{C}$. Membranes were washed three times with TBST (10 min/wash). Following the primary incubation, membranes were incubated with horseradish peroxidase labeled goat anti-rabbit IgG secondary antibody (1:5,000; cat. no. CW0103S; Beijing ComWin Biotech Co., Ltd.) at room temperature for $1 \mathrm{~h}$. Membranes were re-washed three time with TBST (10 min/wash), and protein bands were visualized using a chemiluminescence imaging system (Tanon Science and Technology Co., Ltd.) and normalized to the internal reference gene GAPDH.

Statistical analysis. Every experiment was replicated thrice. Statistical analysis was performed using SPSS 17.0 software (SPSS, Inc.) and data are presented as the mean \pm standard deviation. t-test was used for comparison between two groups and one-way ANOVA was used for comparisons among multiple groups. Homogeneous data were analyzed using the least significant difference test (three groups) or Tukey's post hoc test (more than three groups). Nonhomogeneous data were analyzed using Kruskal-Wallis and Dunn's post hoc tests. $\mathrm{P}<0.05$ was considered to indicate a statistically significant difference.

\section{Results}

Establishment of chronic asthma mouse models. Following sensitization and excitation by OVA, mice in the asthma, GA and dexamethasone groups developed the following symptoms: Shortness of breath, irritability, incontinence, rapid breathing, irregular breathing rhythm, visibly trembling limbs, cyanosis, cough and decreased activity. Conversely, no obvious symptoms were observed among mice in the blank group. Notably, mice in the GA and dexamethasone groups did not vary to a great extent; however, mice in the asthma group had severe symptoms compared with those in the GA and dexamethasone groups. No mice died during this experiment.

The results of H\&E staining are presented in Fig. S1A, which exhibited no remarkable airway inflammation and lung morphology changes in the blank group. However, mice in the asthma group had a significantly thicker airway wall and airway smooth muscle, a broadened strata submucosa, mucosal epithelial hyperplasia and heightened mucus secretion $(\mathrm{P}<0.01$; Fig. S1A and B). In addition, mice in each group were 
Table II. Standard of inflammation score.

\begin{tabular}{|c|c|c|}
\hline Score & Airway inflammatory cells & Alveolar inflammation \\
\hline 0 & No cells & No infection \\
\hline 1 & A few cells & A few macrophages in alveoli \\
\hline 2 & A ring of 1 cell layer deep & $\begin{array}{l}\text { Slight thickening of alveolar walls, more macrophages } \\
\text { and eosinophils in alveoli }\end{array}$ \\
\hline 3 & A ring of 2-4 cells deep & $\begin{array}{l}\text { Significant thickening of alveolar walls, multinucleated } \\
\text { giant cells and eosinophils in } 30-50 \% \text { of alveoli involved }\end{array}$ \\
\hline 4 & A ring of $>4$ cells deep & $\begin{array}{l}\text { Significant thickening of alveolar walls, multinucleated } \\
\text { giant cells and eosinophils in }>50 \% \text { of alveoli involved }\end{array}$ \\
\hline 5 & - & Alveolar consolidation \\
\hline
\end{tabular}

scored in compliance with the scoring directive (Table II) (22), which revealed notable airway inflammation, inflammatory cell infiltration and airway remolding in mice with OVA-induced asthma compared with mice in the blank group $(\mathrm{P}<0.01$; Fig. S1B and $\mathrm{C})$.

Masson staining stained the collagen fiber blue, the muscle fiber cytoplasm red and the nucleus blue/brown. Following Masson staining of the lung tissues, the degree of airway wall thickness (Wat, $\mu \mathrm{m}^{2}$ ), smooth muscle layer (Wam, $\mu \mathrm{m}^{2}$ ), thickness of the inside airway wall (Wai, $\mu \mathrm{m}^{2}$ ) and collagen deposition under the basement membrane ( $\mathrm{Wcol}, \mu \mathrm{m}^{2}$ ) were measured and standardized to the perimeter of the basement membrane $(\mathrm{Pbm})$. The results demonstrated that mice in the asthma group exhibited effectively enhanced deposition of airway collagen fiber in addition to elevated Wat/Pbm, Wam/Pbm, Wai/Pbm and Wcol/Pbm, compared with mice in the blank group ( $\mathrm{P}<0.01$; Fig. S1A and D).

PAS staining was performed to detect goblet cells, and the results demonstrated that there were no PAS-positive goblet cells in the blank group. Conversely, a large number of PAS-positive goblet cells were observed in the airway epithelium of asthmatic mice, causing excessive secretion of airway mucus (Fig. S1A). The PAS-positive area (APAS $\left.{ }^{+} / \mathrm{Pbm}\right)$ of the membrane length $(\mu \mathrm{m})$ was quantitatively measured and the results demonstrated that $\mathrm{APAS}^{+} / \mathrm{Pbm}$ significantly increased in OVA-exposed mice compared with the blank group $(\mathrm{P}<0.01$; Fig. S1E). Taken together, these results exhibited successful establishment of OVA-induced chronic asthma models.

GA attenuates lesions in airways and airway collagen deposition in mice with chronic asthma. As presented in Fig. 1A, mice in the GA and dexamethasone groups exhibited modest airway inflammation, and decreased airway wall and airway smooth muscle layers compared with the asthma group. In addition, lesions in all groups of mice were scored in compliance with the scoring directive (Table II). The results demonstrated that mice in the GA and dexamethasone groups had mitigated airway inflammation, inflammatory cell infiltration and airway remolding compared with the asthma group $(\mathrm{P}<0.05$ and $\mathrm{P}<0.01$; Fig. $1 \mathrm{~B}$ and $\mathrm{C})$.

Masson staining demonstrated that mice in the GA and dexamethasone groups exhibited elevated deposition of airway collagen fiber, as well as mitigated Wat/Pbm, Wam/Pbm, Wai/Pbm and Wcol/Pbm compared with mice in the asthma group ( $\mathrm{P}<0.05$; Fig. $1 \mathrm{~A}$ and $\mathrm{P}<0.01$; Fig. 1D). PAS staining demonstrated that the number of PAS-positive goblet cells significantly decreased in the GA and dexamethasone groups compared with the asthma group, suggesting that GA and dexamethasone decreased airway mucus secretion in asthmatic mice $(\mathrm{P}<0.05$; Fig. $1 \mathrm{~A}$ and $\mathrm{P}<0.01$; Fig. 1E).

GA suppresses inflammation in mice with chronic asthma. ELISA was performed to detect the serum levels of inflammatory cytokines from each group. As presented in Fig. 2, the levels of IL-4, IL-5, IL-13 and IL-17 significantly increased in the asthma group compared with the blank group $(\mathrm{P}<0.01)$, while the GA and dexamethasone groups exhibited lower levels of IL-4, IL-5, IL-13 and IL-17 compared with the asthma group $(\mathrm{P}<0.05)$. Collectively, these results exhibit the anti-inflammatory role of GA in mice with chronic asthma.

GA inhibits the TGF- $\beta 1 /$ Smad signaling pathway in OVA-challenged mice with asthma. mRNA and protein levels of TGF- $\beta 1$, Smad 2 and Smad7 in the lung tissues of mice in each group were assessed via western blot and RT-qPCR analyses. The results demonstrated that both mRNA and protein levels of TGF- $\beta 1$ and Smad 2 significantly increased in the asthma, GA and dexamethasone groups $(\mathrm{P}<0.05$; Fig. 3A, $\mathrm{B}, \mathrm{D}$ and $\mathrm{E}$ ), while there was an obvious decrease in Smad7 mRNA and protein levels compared with the blank group $(\mathrm{P}<0.05$; Fig. 3C-E).

The levels of TGF- $\beta 1$ and Smad 2 significantly decreased ( $\mathrm{P}<0.05$; Fig. 3A, B, D and E), whereas Smad7 was strongly expressed in the GA and dexamethasone groups $(\mathrm{P}<0.05$; Fig. 3C-E) compared with the asthma group. Taken together, these results suggest that GA ameliorates airway inflammation and remodeling by downregulating the TGF- $\beta 1 / \mathrm{Smad}$ signaling pathway in asthma.

Effects of exogenous recombinant TGF- $\beta 1$ on the regulation of GA in asthmatic mice. To further validate the association between GA and the GF- $\beta 1 /$ Smad signaling pathway on airway inflammation and remodeling, mice with chronic asthma were established by intraperitoneal injection of exogenous recombinant TGF- $\beta 1$ and GA. As presented in Fig. 4A, mice in the GA + TGF- $\beta 1$ group had aggravated airway inflammation, as well as thickened airway walls and airway smooth muscle layers compared with the GA group. Inflammation 
A

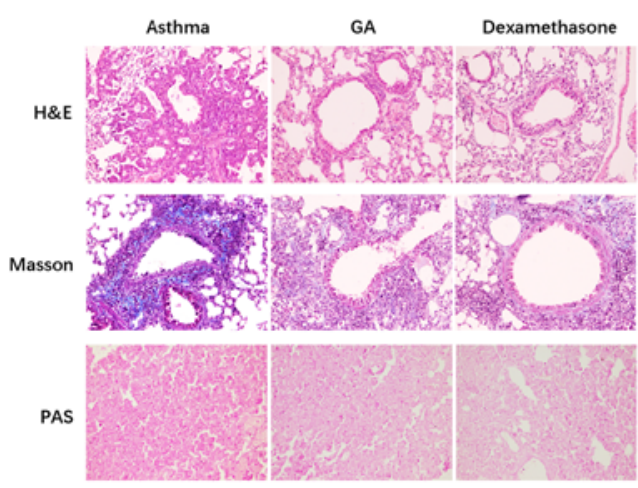

B.

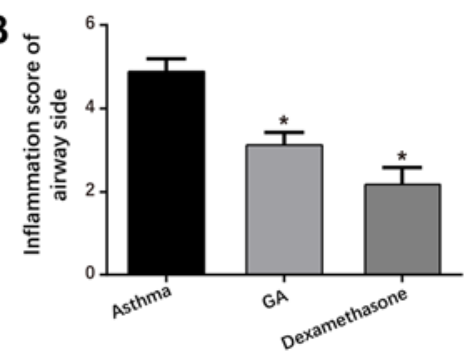

D

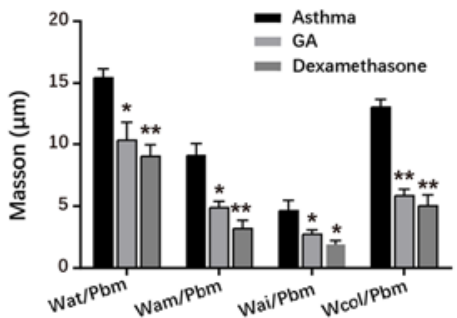

C

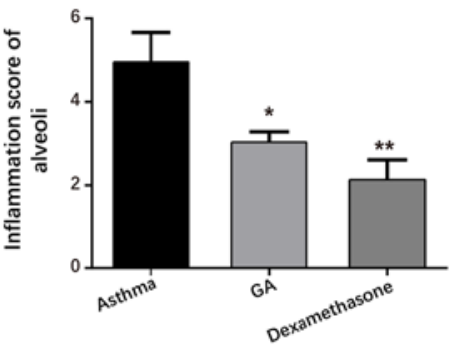

$\mathbf{E}$

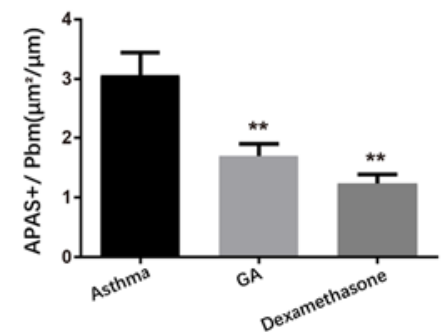

Figure 1. GA prevents lesions in airways and airway collagen deposition in mice with ovalbumin-induced chronic asthma. (A) The pathological changes in the airways and alveolar tissues of mice were determined via H\&E, Masson and PAS staining (magnification, x200). (B) Inflammation score of the airway and airway side in mice of each group. (C) Inflammation score of the pulmonary alveoli in mice of each group. (D) The levels of Wat $/ \mathrm{Pbm}$, Wam/ $\mathrm{Pbm}, \mathrm{Wai} / \mathrm{Pbm}$ and $\mathrm{Wcol} / \mathrm{Pbm}$ were determined via Masson staining. (E) The PAS-positive area per total area was measured. ${ }^{*} \mathrm{P}<0.05,{ }^{* *} \mathrm{P}<0.01 \mathrm{vs}$. asthma group. GA, glycyrrhizic acid; H\&E, hematoxylin and eosin; PAS, periodic acid-Schiff.

A
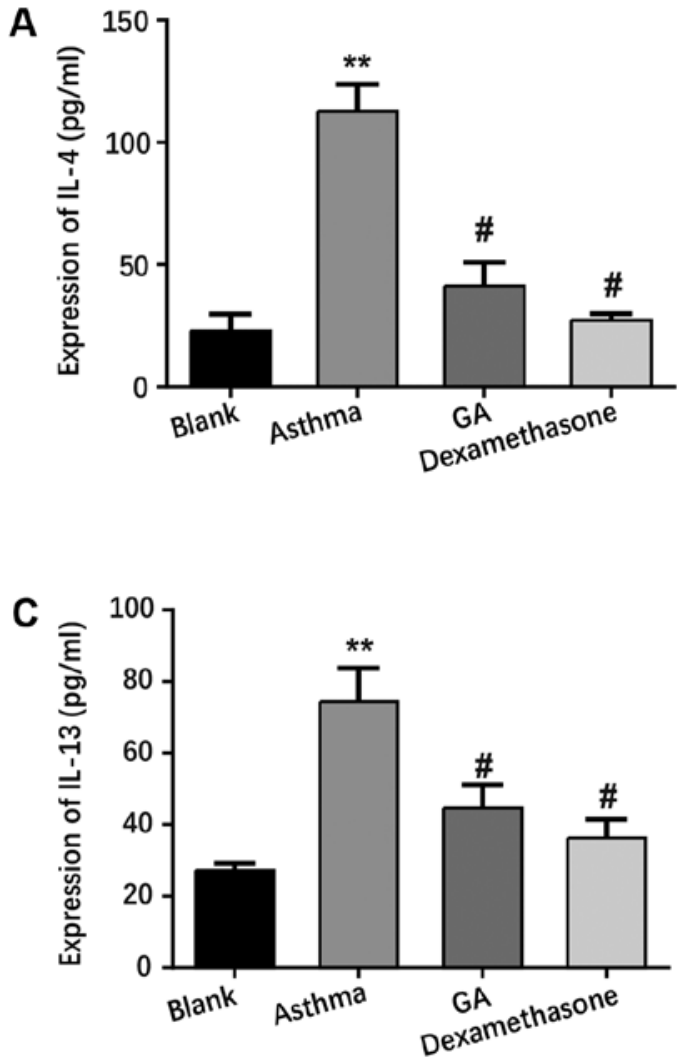

B

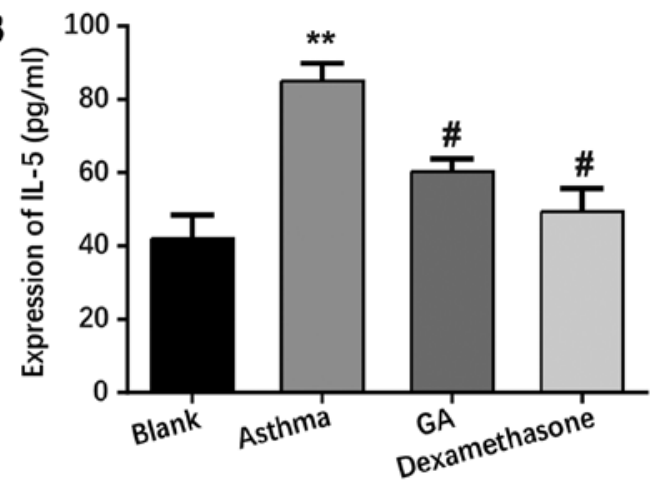

D

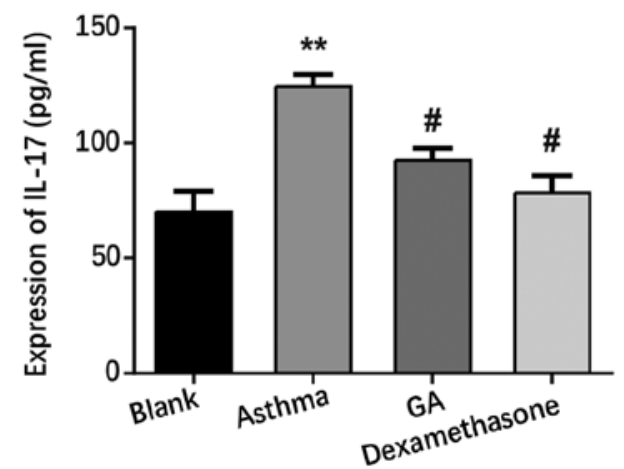

Figure 2. GA suppresses inflammation in mice with ovalbumin-induced chronic asthma. The serum levels of (A) IL-4, (B) IL-5, (C) IL-13 and (D) IL-17 in mice in the asthma, GA and dexamethasone groups were detected via the enzyme-linked immunosorbent assay. ${ }^{* *} \mathrm{P}<0.01$ vs. blank group; ${ }^{\sharp} \mathrm{P}<0.05$ vs. asthma group. GA, glycyrrhizic acid; IL, interleukin.

in all groups of mice was scored (Table II), and the results demonstrated that airway inflammation, inflammatory cell infiltration and airway remolding were considerably exacerbated in mice in the GA + TGF- $\beta 1$ group compared with the GA group $(\mathrm{P}<0.05$; Fig. $4 \mathrm{~B}$ and $\mathrm{C})$.
Masson staining confirmed that there were decreased deposition of airway collagen fiber coupled with increased Wat/Pbm, Wam/Pbm, Wai/Pbm and Wcol/Pbm in the $\mathrm{GA}+$ TGF- $\beta 1$ group compared with the GA group $(\mathrm{P}<0.05$ and $\mathrm{P}<0.01$; Fig. $4 \mathrm{~A}$ and $\mathrm{D}$ ). PAS staining demonstrated that 

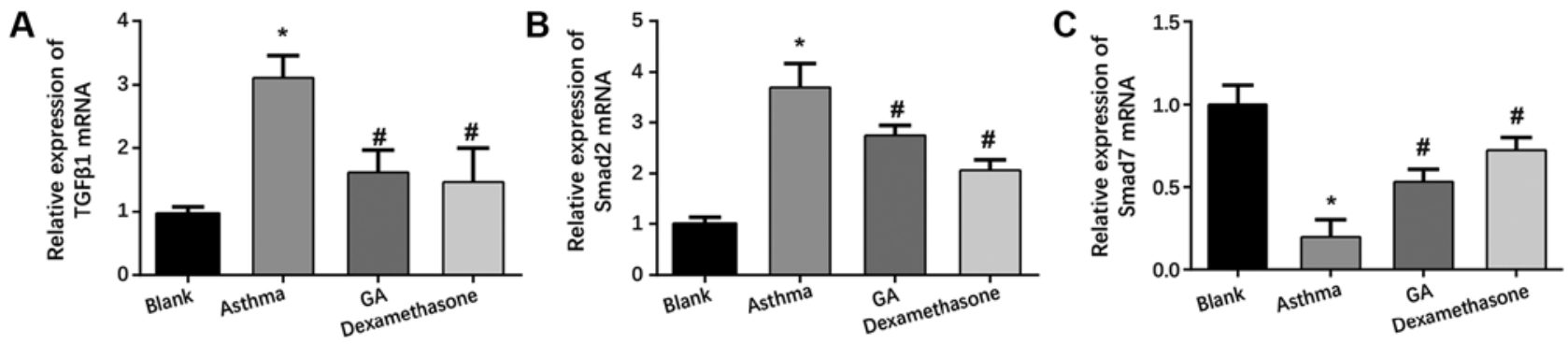

D
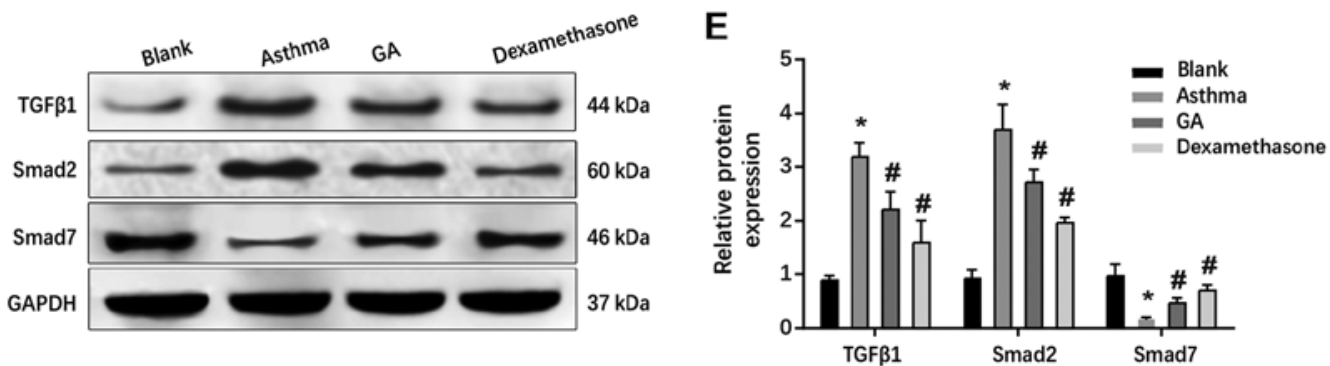

Figure 3. Expression levels of TGF- $\beta 1$, Smad 2 and Smad7 in lung tissues of mice. mRNA levels of (A) TGF- $\beta 1$, (B) Smad2 and (C) Smad7 in mouse lung tissues of each group were detected via reverse transcription-quantitative PCR analysis. (D) Protein levels of TGF- $\beta 1$, Smad 2 and Smad7 in mouse lung tissues of each group were detected via western blot analysis. (E) The gray value of protein bands among groups was assessed. ${ }^{*} \mathrm{P}<0.05$ vs. blank group; ${ }^{\text {}} \mathrm{P}<0.05$ vs. asthma group. TGF- $\beta 1$, transforming growth factor- $\beta 1$.

the number of PAS-positive goblet cells significantly increased in the GA + TGF- $\beta 1$ group compared with the GA group, suggesting that TGF- $\beta 1$ increased airway mucus secretion in asthmatic mice $(\mathrm{P}<0.05$; Fig. $4 \mathrm{~A}$ and $\mathrm{E})$. In addition, ELISA was performed to determine the serum levels of inflammatory cytokines in mice treated with GA alone or with both TGF- $\beta 1$ and GA. The results demonstrated that the levels of IL-4, IL-5, IL-13 and IL-17 significantly increased in the GA + TGF- $\beta 1$ group compared with the GA group $(\mathrm{P}<0.05$ and $\mathrm{P}<0.01$; Fig. 4F-I). Collectively, these results suggest that the anti-inflammatory role of GA in mice with chronic asthma occurs by downregulating the TGF- $\beta 1 /$ Smad signaling pathway.

\section{Discussion}

Immense efforts have been made for asthma therapy; however, due to the heterogenicity and complexity of asthma, effectively controlling asthma remains difficult (23). Previous studies have demonstrated that GA ameliorates asthma and other human disease symptoms including septic acute kidney injury, liver injury and lung injury (14,24-26). Thus, the present study aimed to investigate the therapeutic effects of GA on airway inflammation and remodeling in asthmatic mice and determine its underlying molecular mechanism in asthma. Taken together, the results of the present study suggest that GA may exert anti-asthmatic effects in mice by modulating the TGF- $\beta 1 /$ Smad signaling pathway.

$\mathrm{H} \& \mathrm{E}$ staining demonstrated an elevated number of airway smooth muscle cells, and the smooth muscle layer was notably thickened in mice following OVA treatment. Consistent with findings of a previous report (27), Masson staining indicated that intrapulmonary bronchial Wat/Pbm, Wam/Pbm, Wai/Pbm and Wcol/Pbm increased in the OVA-sensitized group compared with the blank group. Furthermore, PAS staining demonstrated that there was a large number of PAS-positive goblet cells in the airway epithelium of asthmatic mice. Thus, the present study successfully established an asthma model in mice.

Currently, the anti-inflammatory role of GA has received increasing attention $(28,29)$. In addition, it has been demonstrated that GA can alleviate the symptoms of allergic asthma (30). The results of the present study demonstrated that the ratios of Wat $/ \mathrm{Pbm}$, Wam/Pbm, Wai/Pbm and Wcol/Pbm significantly decreased in the GA and dexamethasone groups compared with those in the asthma group. This suggests that GA may suppress increased thickness in the airway wall and smooth muscle, yielding a positive effect on improving airway remodeling. Similarly, the number of PAS-positive goblet cells significantly decreased in the GA and dexamethasone groups in contrast to the asthma group, suggesting that GA and dexamethasone may decrease airway mucus secretion in asthmatic mice. In addition, the levels of IL-4, IL-5, IL-13 and IL-17 were significantly lower in the GA and dexamethasone groups compared with the asthma group, indicating that GA may suppress the inflammatory response in chronic asthma.

Increasing evidence have demonstrated that the TGF- $\beta 1 /$ Smad signaling pathway is considered one of the most essential molecular mechanisms for airway remodeling in asthma (15,31-33). TGF- $\beta 1$ is a profibrotic cytokine that is believed to exert a critical role in chronic asthma (34). The Smad family of proteins is the only proven substrate acted by the TGF- $\beta 1$ receptor (35), and also the Smad protein has been reported to modulate the intracellular mediators for TGF- $\beta 1$ signaling (36). In addition, previous studies have reported that TGF- $\beta 1$ may have several biological effects via the activation of downstream mediators, such as Smad2, Smad 3 and Smad4, and TGF- $\beta 1$ is negatively regulated by Smad7 expression (37-39). The results of the present study demonstrated that TGF- $\beta 1$ and Smad 2 mRNA and protein levels notably increased in mouse lung tissues in each group, while opposite effects were observed 

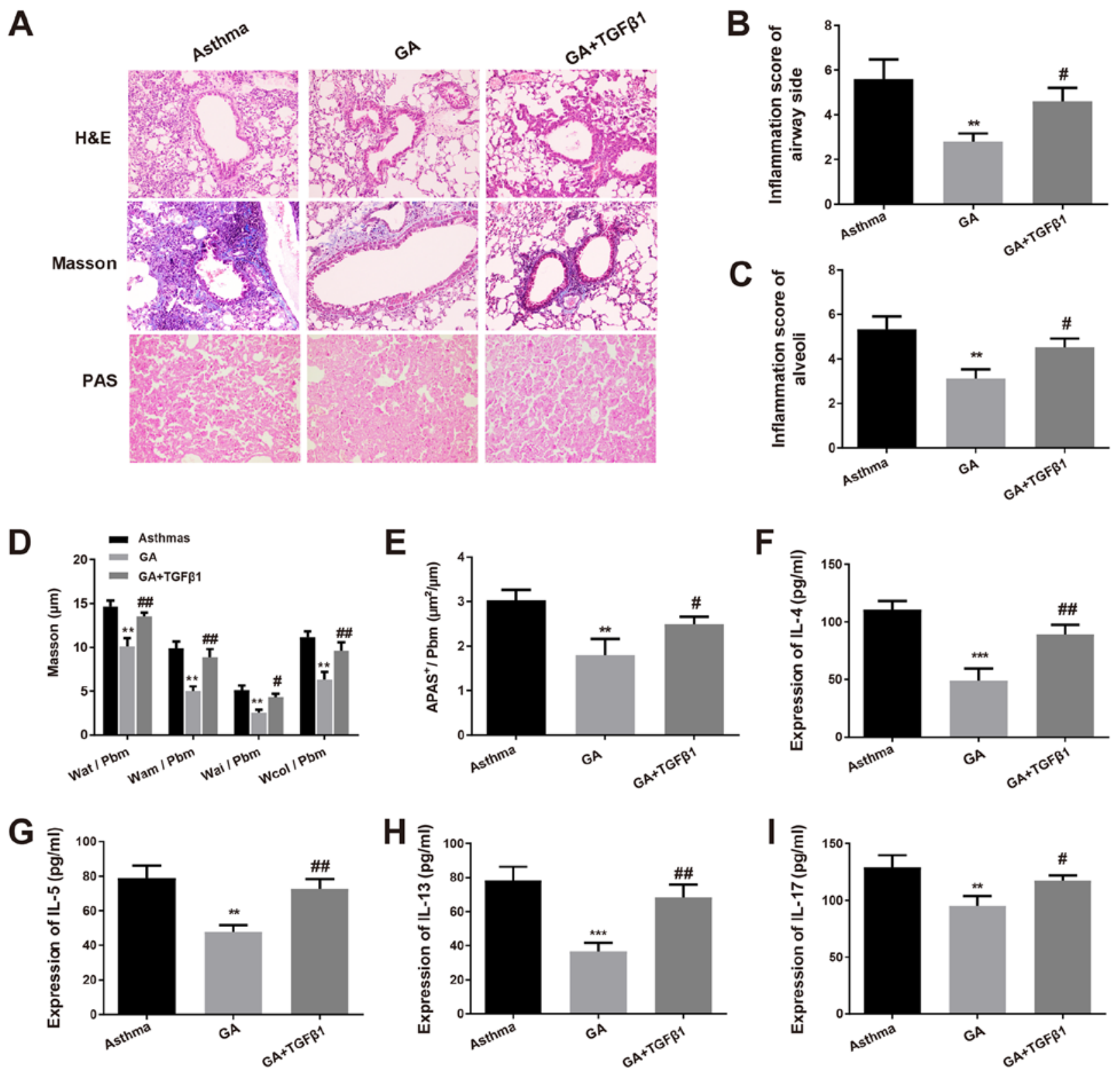

Figure 4. Effects of TGF- $\beta 1$ in asthmatic mice. (A) H\&E, Masson and PAS staining (magnification, x200) were performed to determine the pathological changes in the airways and alveolar tissues of mice. (B) Inflammation of the airway and airway side, as well as (C) pulmonary alveoli in mice of each group were detected. (D) Masson staining was performed to determine the levels of Wat/Pbm, Wam/Pbm, Wai/Pbm and Wcol/Pbm. (E) The PAS-positive area per total area was measured. The serum levels of (F) IL-4, (G) IL-5, (H) IL-13 and (I) IL-17 in mice of each group were detected via the enzyme-linked immunosorbent assay. ${ }^{* *} \mathrm{P}<0.01,{ }^{* * *} \mathrm{P}<0.001$ vs. asthma group; ${ }^{\#} \mathrm{P}<0.05,{ }^{\# \#} \mathrm{P}<0.01$ vs. GA group. TGF- $\beta 1$, transforming growth factor- $\beta 1$; H\&E, hematoxylin and eosin; PAS, periodic acid-Schiff; IL, interleukin; GA, glycyrrhizic acid.

following GA treatment. Furthermore, as an inhibitory Smad protein, Smad7 blocks TGF- $\beta$ signaling through a negative feedback loop (40). The present results showed that Smad7 exerted an inhibitory role in asthmatic mouse, and this inhibitory effect was enhanced by GA treatment. Taken together, GA effectively promoted Smad7 mRNA and protein expression, and downregulated the levels of TGF- $\beta 1$ and $\operatorname{Smad} 2$ in the lung tissues of mice with asthma. Thus, the TGF- $\beta 1 / \mathrm{Smad}$ signaling pathway may be a novel therapeutic approach for controlling asthma airway remodeling.

The present study also aimed to determine whether the TGF- $\beta 1 /$ Smad signaling pathway was implicated in the regulation of GA on airway inflammation and remodeling. A previous study reported that OVA-challenged mouse fibroblasts undergo morphological alterations in response to exogenous TGF- $\beta 1$ stimulation (41). In the present study, exogenous TGF- $\beta 1$ in combination with GA were intraperitoneally injected into asthmatic mice to detect airway inflammation and remodeling. As expected, exogenous TGF- $\beta 1$ significantly increased airway inflammation, inflammatory cell infiltration and airway remolding, accompanied by decreased deposition of airway collagen fiber and increased Wat/Pbm, Wam/Pbm, Wai/Pbm and Wcol/Pbm, which also resulted in the promotion of airway mucus secretion and inflammatory cytokines in asthmatic mice. Taken together, these results suggest that GA inhibits asthma airway remodeling in mice with asthma at least partly via inactivation of the TGF- $\beta 1 / \mathrm{Smad}$ signaling pathway.

In conclusion, the present study demonstrated that GA is closely associated with chronic asthma development, and its 
underlying molecular mechanism was investigated. To the best of our knowledge, the present study was the first to demonstrate that GA may suppress chronic asthma, at least in part via the inhibition of TGF- $\beta 1$ and Smad2, as well as upregulation of Smad7 expression in mice with asthma. Collectively, the results of the present study indicate that GA attenuates airway inflammation and remodeling in asthma mainly through the TGF- $\beta /$ Smad signaling pathway, suggesting that GA may be used as a medical treatment for chronic asthma. However, the present study was not without limitations. The present findings had only been investigated in vitro and in vivo, and more data are required to validate the results of our study before those treatments yield benefits in the clinic. Prospective studies will perform in vitro experiments and deeper analysis to further substantiate the specific target cells for GA treatment of asthma.

\section{Acknowledgements}

Not applicable.

\section{Funding}

No funding was received.

\section{Availability of data and materials}

The datasets used and.or analyzed during the present study are available from the corresponding author on reasonable request.

\section{Authors' contributions}

ZY and YF conceived the study and designed and performed the experiments. ZY analyzed the data and wrote the manuscript. YF provided critical materials and supervised the study. All authors read and approved the final manuscript.

\section{Ethics approval and consent to participate}

All animal experiments were approved by the local Ethics Committee of Beijing University of Chinese Medicine (approval no. A-20190821006) and performed in accordance with the Guide for the Care and Use of Laboratory Animals.

\section{Patients consent for publication}

Not applicable.

\section{Competing interests}

The authors declare that they have no competing interests.

\section{References}

1. Papi A, Brightling C, Pedersen SE and Reddel HK: Asthma. Lancet 391: 783-800, 2018.

2. Zhu X, Li Q, Hu G, Wang J, Hu Q, Liu Z, Wu G and Zhong Y: BMS345541 inhibits airway inflammation and epithelialmesenchymal transition in airway remodeling of asthmatic mice. Int J Mol Med 42: 1998-2008, 2018.
3. Jo A, Lee SH, Kim DY, Hong SJ, Teng MN, Kolliputi N, Lockey RF, Schleimer RP and Cho SH: Mast cell-derived plasminogen activator inhibitor type 1 promotes airway inflammation and remodeling in a murine model of asthma. J Allergy Clin Immunol 142: 294-297.e5, 2018.

4. Gupta A, Chakraborty S and Agrawal A: Molecular and Genomic Basis of Bronchial Asthma. In: Clinical Molecular Medicine. Academic Press, pp353-366, 2020.

5. Wu P, Xu B, Shen A, He Z, Zhang CJ, Ming WK and Shen K: The economic burden of medical treatment of children with asthma in China. BMC Pediatr 20: 386, 2020.

6. Bao Z, Zhang P, Yao Y, Lu G, Tong Z, Yan B, Tu L, Yang G and Zhou J: Deguelin attenuates allergic airway inflammation via inhibition of NF- $\mathrm{KB}$ pathway in mice. Int J Biol Sci 13: 492-504, 2017.

7. Cho IH, Choi YJ, Gong JH, Shin D, Kang MK and Kang YH: Astragalin inhibits autophagy-associated airway epithelial fibrosis. Respir Res 16: 51, 2015.

8. Li Y, Wang H and Yang X: Effects of catalpol on bronchial asthma and its relationship with cytokines. J Cell Biochem 120 8992-8998, 2019.

9. Sung JE, Lee HA, Kim JE, Yun WB, An BS, Yang SY, Kim DS, Lee CY, Lee HS, Bae CJ and Hwang DY: Saponin-enriched extract of Asparagus cochinchinensis alleviates airway inflammation and remodeling in ovalbumin-induced asthma model. Int J Mol Med 40: 1365-1376, 2017.

10. Fouladi S, Masjedi M, Ghasemi R, Hakemi MG and Eskandari N: The in vitro impact of glycyrrhizic acid on $\mathrm{CD} 4^{+} \mathrm{T}$ lymphocytes through OX40 receptor in the patients with allergic rhinitis. Inflammation 41: 1690-1701, 2018.

11. Qu L, Chen C, He W, Chen Y, Li Y, Wen Y, Zhou S, Jiang Y, Yang X, Zhang R and Shen L: Glycyrrhizic acid ameliorates LPS-induced acute lung injury by regulating autophagy through the PI3K/AKT/mTOR pathway. Am J Transl Res 11: 2042-2055, 2019.

12. Su X, Wu L, Hu M, Dong W, Xu M and Zhang P: Glycyrrhizic acid: A promising carrier material for anticancer therapy. Biomed Pharmacother 95: 670-678, 2017.

13. Gao L, Tang H, He H, Liu J, Mao J, Ji H, Lin H and Wu T: Glycyrrhizic acid alleviates bleomycin-induced pulmonary fibrosis in rats. Front Pharmacol 6: 215, 2015.

14. Wu Q, Tang Y, Hu X, Wang Q, Lei W, Zhou L and Huang J: Regulation of Th1/Th2 balance through OX40/OX40L signalling by glycyrrhizic acid in a murine model of asthma. Respirology 21 : 102-111, 2016.

15. Liu YD, Sun $X$, Zhang $Y$, Wu HJ, Wang $H$ and Yang R: Protocatechuic acid inhibits TGF-betal-induced proliferation and migration of human airway smooth muscle cells. J Pharmacol Sci 139: 9-14, 2019.

16. Ojiaku CA, Yoo EJ and Panettieri RA Jr: Transforming growth factor $\beta 1$ function in airway remodeling and hyperresponsiveness. The missing link? Am J Respir Cell Mol Biol 56: 432-442, 2017.

17. Macias MJ, Martin-Malpartida P and Massague J: Structural determinants of Smad function in TGF- $\beta$ signaling. Trends Biochem Sci 40: 296-308, 2015.

18. van der Kraan PM: Differential role of transforming growth factor-beta in an osteoarthritic or a healthy joint. J Bone Metab 25: 65-72, 2018.

19. Ogden BE, Pang William W, Agui T and Lee BH: Laboratory animal laws, regulations, guidelines and standards in China Mainland, Japan, and Korea. ILAR J 57: 301-311, 2016.

20. Shi YX, Dai X and Wang LJ, et al: Effect of ligustrazine on airway inflammation and airway remodeling in asthmatic mice by regulating TGF- $\beta 1 /$ Smad signaling pathway. Drugs Clinic 1: 20-26, 2019.

21. Livak KJ and Schmittgen TD: Analysis of relative gene expression data using real-time quantitative PCR and the 2(-Delta Delta C(T)) method. Methods 25: 402-408, 2001.

22. Nakagami Y, Favoreto S Jr, Zhen G, Park SW, Nguyenvu LT, Kuperman DA, Dolganov GM, Huang X, Boushey HA, Avila PC and Erle DJ: The epithelial anion transporter pendrin is induced by allergy and rhinovirus infection, regulates airway surface liquid, and increases airway reactivity and inflammation in an asthma model. J Immunol 181: 2203-2210, 2008.

23. Blasi F, Bettoncelli G, Canonica GW, Centanni S, Crimi N, DiMaria G, Gasparini S, Gentili G, Girbino G, Mereu C, et al: The management of asthma in the phenotype and biomarker era: The proposal of a new diagnostic-therapeutic model. J Asthma 53: 665-667, 2016. 
24. Liang B, Guo XL, Jin J, Ma YC and Feng ZQ: Glycyrrhizic acid inhibits apoptosis and fibrosis in carbon-tetrachloride-induced rat liver injury. World J Gastroenterol 21: 5271-5280, 2015.

25. Zhao H, Liu Z, Shen H, Jin S and Zhang S: Glycyrrhizic acid pretreatment prevents sepsis-induced acute kidney injury via suppressing inflammation, apoptosis and oxidative stress. Eur J Pharmacol 781: 92-99, 2016.

26. Zhao H, Zhao M, Wang Y, Li F and Zhang Z: Glycyrrhizic acid prevents sepsis-induced acute lung injury and mortality in rats. J Histochem Cytochem 64: 125-137, 2016.

27. Tang X, Nian H, Li X, Yang Y, Wang X, Xu L, Shi H, Yang X and Liu R: Effects of the combined extracts of Herba epimedii and Fructus Ligustrilucidi on airway remodeling in the asthmatic rats with the treatment of budesonide. BMC Complement Altern Med 17: 380, 2017.

28. Pang H, Huang T, Song J, Li D, Zhao Y and Ma X: Inhibiting HMGB1 with glycyrrhizic acid protects brain injury after DAI via its anti-inflammatory effect. Mediators Inflamm 2016 4569521,2016

29. Yu JY, Ha JY, Kim KM, Jung YS, Jung JC and Oh S: Anti-inflammatory activities of licorice extract and its active compounds, glycyrrhizic acid, liquiritin and liquiritigenin, in BV2 cells and mice liver. Molecules 20: 13041-13054, 2015.

30. Fouladi S, Masjedi M, Ganjalikhani Hakemi M and Eskandari N The review of in vitro and in vivo studies over the glycyrrhizic acid as natural remedy option for treatment of allergic asthma. Iran J Allergy Asthma Immunol 18: 1-11, 2019.

31. Wang C, Zheng M, Choi Y, Jiang J, Li L, Li J, Xu C, Xian Z, Li Y, Piao H, et al: Cryptotanshinone attenuates airway remodeling by inhibiting crosstalk between tumor necrosis factor-like weak inducer of apoptosis and transforming growth factor beta 1 signaling pathways in asthma. Front Pharmacol 10: 1338, 2019.

32. Lee HY, Kim IK, Yoon HK, Kwon SS, Rhee CK and Lee SY: Inhibitory effects of resveratrol on airway remodeling by transforming growth factor-beta/Smad signaling pathway in chronic asthma model. Allergy Asthma Immunol Res 9: 25-34, 2017.
33. Qu ZH, Yang ZC, Chen L, Lv ZD, Yi MJ and Ran N: Inhibition airway remodeling and transforming growth factor- $\beta 1 / \mathrm{Smad}$ signaling pathway by astragalus extract in asthmatic mice. Int J Mol Med 29: 564-568, 2012.

34. Jeon WY, Shin IS, Shin HK, Jin SE and Lee MY: Aqueous extract of Gumiganghwal-tang, a traditional herbal medicine, reduces pulmonary fibrosis by transforming growth factor- $\beta 1 /$ Smad signaling pathway in murine model of chronic asthma. PLoS One 11: e0164833, 2016.

35. Feng Y, Yang C, Yang W and Jiang T: Effect of dexamethasone on TGF- $31 /$ Smad3 signalling pathway in airway remodelling model of asthmatic rats. J Coll Physicians Surg Pak 29: 537-540, 2019.

36. Wang J, Li HY, Wang HS and Su ZB: MicroRNA-485 modulates the TGF- $\beta /$ Smads signaling pathway in chronic asthmatic mice by targeting Smurf2. Cell Physiol Biochem 51: 692-710, 2018.

37. Chen L, Yang T, Lu DW, Zhao H, Feng YL, Chen H, Chen DQ, Vaziri ND and Zhao YY: Central role of dysregulation of TGF- $\beta /$ Smad in CKD progression and potential targets of its treatment. Biomed Pharmacother 101: 670-681, 2018.

38. Hu HH, Chen DQ, Wang YN, Feng YL, Cao G, Vaziri ND and Zhao YY: New insights into TGF- $\beta /$ Smad signaling in tissue fibrosis. Chem Biol Interact 292: 76-83, 2018.

39. Walton KL, Johnson KE and Harrison CA: Targeting TGF- $\beta$ mediated SMAD signaling for the prevention of fibrosis. Front Pharmacol 8: 461, 2017.

40. Briones-Orta MA, Tecalco-Cruz AC, Sosa-Garrocho M, Caligaris $C$ and Macias-Silva M: Inhibitory Smad7: Emerging roles in health and disease. Curr Mol Pharmacol 4: 141-153, 2011.

41. Sugiura H, Liu X, Duan F, Kawasaki S, Togo S, Kamio K, Wang XQ, Mao L, Ahn Y, Ertl RF, et al: Cultured lung fibroblasts from ovalbumin-challenged 'asthmatic' mice differ functionally from normal. Am J Respir Cell Mol Biol 37: 424-430, 2007.

This work is licensed under a Creative Commons

Attribution-NonCommercial-NoDerivatives 4.0 International (CC BY-NC-ND 4.0) License. 